\title{
A Reliable Method to Quantify Trimethoprim and Sulfamethoxazole in Plasma of Children by HPLC with Application in Pharmacokinetic Studies
}

\section{Alejandra Toledo López ${ }^{1}$, Hugo Juárez Olguín ${ }^{*}$, Ismael Lares-Asseff², Fernanda Reyes González¹, Radames Alemon Medina1, Gabriela Pérez Guillé1, Francisca Trujillo Jimenez ${ }^{1}$}

${ }^{1}$ Laboratory of Pharmacology, Instituto Nacional de Pediatría, Mexico City, Mexico

${ }^{2}$ Centro de Investigación Interdisciplinario para el Desarrollo Integral Regional, Durango, Mexico

Email: *juarezol@yahoo.com

How to cite this paper: López, A.T., Olguín, H.J., Lares-Asseff, I., González, F.R., Medina, R.A., Guillé, G.P. and Jimenez, F.T. (2019) A Reliable Method to Quantify Trimethoprim and Sulfamethoxazole in Plasma of Children by HPLC with Application in Pharmacokinetic Studies. American Journal of Analytical Chemistry, 10, 247-253.

https://doi.org/10.4236/ajac.2019.107019

Received: April 8, 2019

Accepted: July 1, 2019

Published: July 4, 2019

Copyright $\odot 2019$ by author(s) and Scientific Research Publishing Inc. This work is licensed under the Creative Commons Attribution-NonCommercial International License (CC BY-NC 4.0). http://creativecommons.org/licenses/by-nc/4.0/ (c) (i) (9) Open Access

\begin{abstract}
Aim: To develop a simple and sensitive high-performance liquid chromatography method to determine plasmatic levels of trimethoprim/sulfamethoxazole in paediatric population. Method: Chromatographic separation was carried out using a reverse phase column with detection ultraviolet at a wavelength of $225 \mathrm{~nm}$. The mobile phase consists of phosphate buffer $0.1 \mathrm{M}$, acetonitrile and methanol, (65:20:15) with a flow of $1.0 \mathrm{ml} / \mathrm{min}$. Results: Calibration curve was linear over the concentration range for trimethoprim of 0.25 to 5 $\mu \mathrm{g} / \mathrm{ml}$ and 5 to $100 \mu \mathrm{g} / \mathrm{ml}$ for sulfamethoxazole. Precision were found to be within $15 \%$ for both compounds. The detection limits and quantifications for trimethoprim/sulfamethoxazole were $0.2-0.25 \mu \mathrm{g} / \mathrm{ml}$ and $3-5 \mu \mathrm{g} / \mathrm{ml}$ respectively. Conclusions: The developed method was applied for the quantification of both compounds in plasma samples of two patients resulting concentrations within the therapeutic ranges. The method is convenient for pharmacokinetic studies.
\end{abstract}

\section{Keywords}

Children, Liquid Chromatography, Phase Reverse, Pharmacokinetics

\section{Introduction}

Trimethoprim-Sulfamethoxazole (TMP/SMX) is a combination of two synthetic antibiotics widely known and studied for more than 25 years [1] [2]. TMP is lipophilic and a weak base with $7.4 \mathrm{pKa}$. This explains its high volume of distri- 
bution (Vd) in comparison with SMX which is even more hydrophilic and a weak acid with $6.0 \mathrm{pKa}$ [1]. The combination of TMP/SMX is used in a proportion of 1:5 which produces concentrations in plasma in the proportion of 1:20, amount that gives an increase in optimum antibacterial activity. Individually, both TMP/SMX are efficient antibacterial drugs of the family of folate antagonists. In children the dose varies from $3 \mathrm{mg} / \mathrm{kg} / 8 \mathrm{~h}$ to $4 \mathrm{mg} / \mathrm{kg} / 12 \mathrm{~h} \mathrm{[1]} \mathrm{[2].} \mathrm{TMP/SMX} \mathrm{is}$ effective for: Staphylococcus, Streptococuus, Enterobacteriaceas, Salmonella, Shigella, Haemophilus influenza, treatment of Pneumocystis carinii in patients with HIV and many different species [1] [2] [3] [4]. The combination of these drugs continued to be one of the most used antibiotics in the clinic.

Several analytical methods for the quantification of these compounds with UV detection, mass spectrometry or by electrophoresis have been developed. Previous HPLC methods have the inconvenient that the retention time is a little more prolonged or that the extraction process is more tedious or not quantified small unities [5] [6] [7] [8]. The objective of the present study was to develop a simple, economical, precise, fast and exact method of HPLC for simultaneous determination of TMP/SMX for pharmacokinetic studies.

\section{Methods}

\subsection{Chromatographic System}

A chromatographic system composed of 515 pump model 717, an automatic injector model 486, a variable-wavelength UV-VI detector, XBridge reversed-phase $\mathrm{C}_{18}$ analytical column $(150 \times 4.6 \mathrm{~mm}$ I.D. $)$ particle size $5 \mu \mathrm{m}$. The data were analysed in a PC with acquisition Millennium program ${ }^{32}$. All equipments were Waters Corp. ${ }^{\mathrm{TM}}$, USA.

\subsection{Chemicals and Reagents}

TMP/SMX, and Sulfamethazine USP grade were obtained from Sigma. Anhydrous sodium phosphate, perchloric acid, acetic acid, water, acetonitrile and methanol (HPLC grade) were purchased from J.T. Baker all other chemicals and solvents used were of analytical grade. Standard solutions for the compounds trimethoprim $(1 \mathrm{mg} / \mathrm{ml})$, sulfamethoxazole $(2 \mathrm{mg} / \mathrm{ml}$.) were prepared and sulfamethazine $(1 \mathrm{mg} / \mathrm{ml})$ was used as internal standard (IS). The compounds were dissolved in methanol and used to prepare the concentrations for calibration curve in plasma with a concentration range of 0.25 to $5 \mu \mathrm{g} / \mathrm{ml}$ for TMP and of 5 to $100 \mu \mathrm{g} / \mathrm{ml}$ for SMX. The internal standard was prepared at a concentration of $10 \mu \mathrm{g} / \mathrm{ml}$. The mobile phase consists of phosphate buffer $0.1 \mathrm{M}$, acetonitrile and methanol all in the following proportion: 65:20:15 respectively, and was added $1 \mathrm{ml}$ of acetic acid. The phase was pumped at a flow-rate of $1 \mathrm{ml} / \mathrm{min}$ using a wavelength of $225 \mathrm{~nm}$ and a massive injection volume of $150 \mu \mathrm{l}$. Extraction procedure is based on protein precipitations. To an aliquot of $200 \mu \mathrm{l}$ of plasma containing a known concentration of TMP/SMX, $20 \mu \mathrm{l}$ of internal standard were added. For protein precipitation, $800 \mu \mathrm{l}$ of perchloric acid $0.33 \mathrm{M}$ were added to 
the mixture and shaken to maximum speed in vortex for $1 \mathrm{~min}$. It was then centrifuged at 4500 revolutions per minute for $10 \mathrm{~min}$. The supernatant was separated and transferred to a micro-vial and from this was injected $150 \mu \mathrm{l}$ to chromatographic system.

\subsection{Assay Validation}

Validation of the method shown later, was carried out according to the guidelines published in the Official Mexican Norm NOM-177-1998 [9]. The calibration curve in plasma was carried out with the following equivalent points 0.25 , $0.5,1,2,4,5 \mu \mathrm{g} / \mathrm{ml}$ for TMP and $5,10,20,40,80$, and $100 \mu \mathrm{g} / \mathrm{ml}$ for SMX. In each proof, a sample of blank plasma (obtained from healthy blood bank donors) processed without standard, was analysed to confirm the absence of interference. Quality control samples (QC) were prepared in plasma in concentrations of 0.4:15 (low control), 1.5:30 (medium control), and 4.5:90 (high control) in $\mu \mathrm{g} / \mathrm{ml}$ for Trimethoprim and Sulfamethoxazole respectively. The internal standard concentration of sulfamethazine was $10 \mu \mathrm{g} / \mathrm{ml}$. The variability parameters for intra- and inter-day were determined in order to evaluate the precision and accuracy of the method. For intra-day variability the following concentrations, 0.4:15 (low control), 1.5:30 (medium control) and 4.5:90 (high control) in $\mu \mathrm{g} / \mathrm{ml}$ for TMP and SMX respectively were analysed in six folds on the same day. With regard to inter-day variability, the same concentrations for trimethoprim and sulfamethoxazole were analysed in triplicate over three consecutive days.

Absolute recovery was determined as the percentage of drug by extracting both compounds from the plasma and the resulting solution $(n=6)$ compared to the drug dissolved in methanol. To evaluate selectivity of method the following compounds in plasma: acetylsalicylic acid, salicylic acid, acetaminophen, ibuprofen, paracetamol and heparin, were assayed in order to detect possible interferences of the compounds under study, and from other medication administered concomitantly. The latter was considered important since interference in quantification of the compound being analysed should be zero.

\section{Results}

Figure 1 shows a typical chromatogram from plasma without application of standard of TMP/SMX and from a sample obtained of a pharmacokinetic study. The retention times of TMP and SMX are 3.7 and 6.8 respectively and $4.4 \mathrm{~min}$ for the internal standard. The execution time of total HPLC was $10 \mathrm{~min}$. No kind of interference in white plasma samples was seen. The prepared calibration curves for TMP/SMX in plasma were linear and additional parameters for the validation are shown in Table 1 . The method is found to be selective on injecting them with other compounds (acetylsalicylic acid, salicylic acid, acetaminophen, ibuprofen, paracetamol and heparin) as shown too in Figure 1 . Both compounds were stable for at least 60 days at $-4^{\circ} \mathrm{C}$ and 120 days at $-70^{\circ} \mathrm{C}$. To evaluate if the method was applicable, the quantification of the levels of 

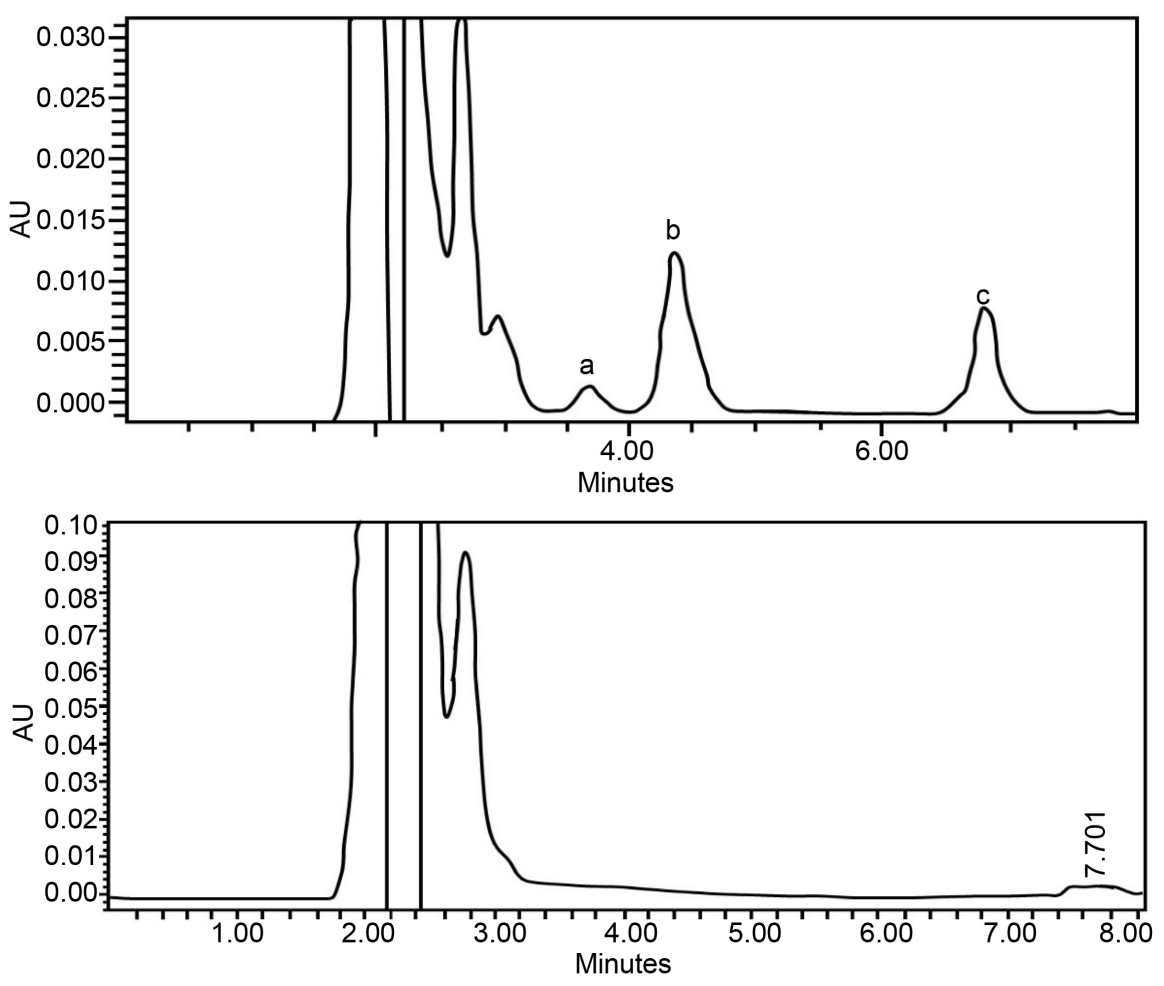

Figure 1. Typical chromatogram from solutions of TMP/SMX and blank plasma. In the first chromatogram (top) are identified the retention times as follow: 3.7 for TMP (a), 4.4 for sulfamethazine as internal standard (b) and 6.8 for SMX (c). And the second (bottom) shows a typical chromatogram of a sample of plasma without the addition of the compounds of interest (blank plasma).

Table 1. Parameters assayed for validation of trimethoprim/sulfamethoxazole.

\begin{tabular}{ccc}
\hline Parameters & Trimethoprim & Sulfamethoxazole \\
\hline Linearity & $\mathrm{r}=0.9998$ & $\mathrm{r}=0.9996$ \\
& Accuracy $98.73 \%$ & Accuracy $98.51 \%$ \\
CV $(\%) 3.6$ & \\
CV $(\%) 3.9$ \\
Precision and accuracy & $\begin{array}{c}\text { Intra-day CV } 2.95 \% \\
\text { Inter-day CV 6.1\% }\end{array}$ & Intra-day CV 3.02\% \\
Recovery & $92.23 \%$ & $96.85 \%$ \\
Limit of detection & $0.2 \mu \mathrm{g} / \mathrm{ml}$ & $3 \mu \mathrm{g} / \mathrm{ml}$ \\
Limit of quantification & $0.25 \mu \mathrm{g} / \mathrm{ml}$ & $5 \mu \mathrm{g} / \mathrm{ml}$
\end{tabular}

trimethoprim and sulfamethoxazole in plasma of two patients from the Infectology Service of National Institute of Paediatrics with a diagnosis of urinary tract infection (UTI) was carried out. The two patients were treated with TMP/SMX with 150/750 mg/m²/12h. Patient 1 had $0.296 \mu \mathrm{g} / \mathrm{ml}$ of TMP and $16.727 \mu \mathrm{g} / \mathrm{ml}$ of SMX and patient $2 \mathrm{had} 1.183 \mu \mathrm{g} / \mathrm{ml}$ and $26.078 \mu \mathrm{g} / \mathrm{ml}$, of trimethoprim and sulfamethoxazole respectively (Figure 2). 

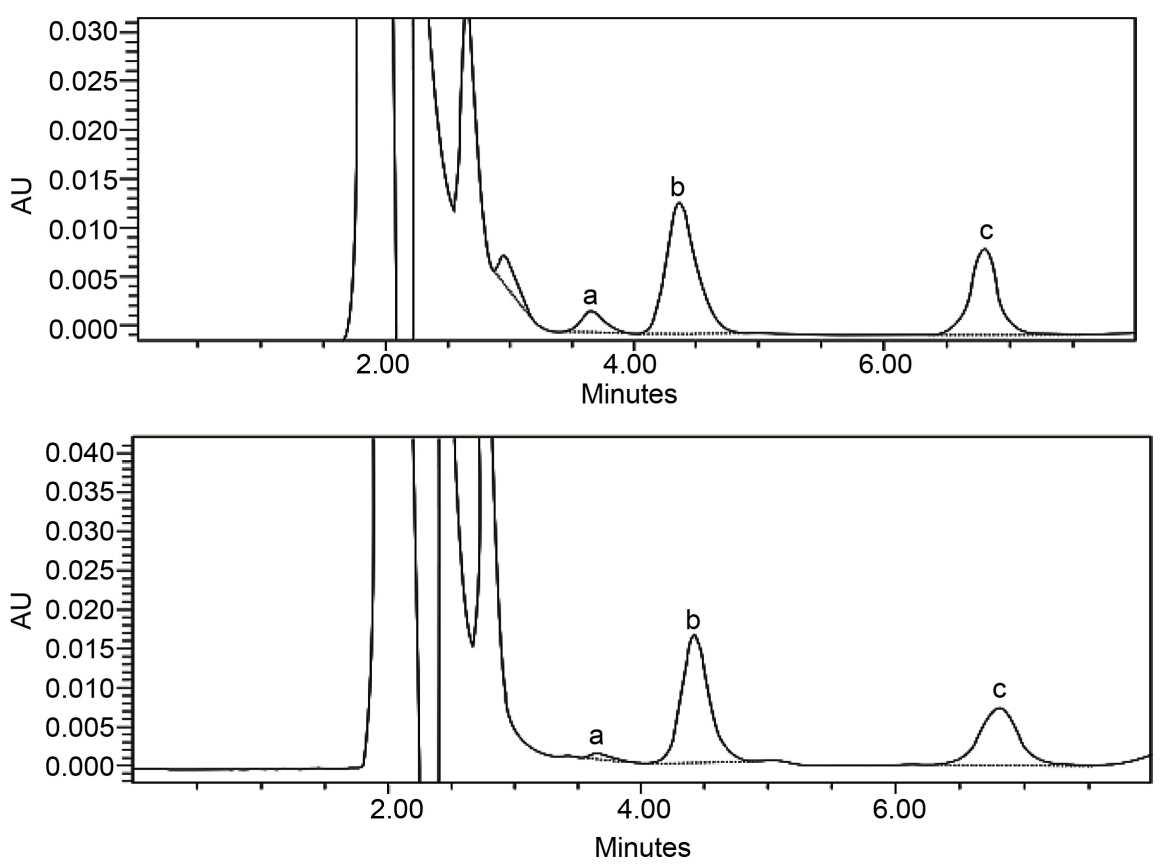

Figure 2. Chromatograms of trimethoprim and sulfamethoxazole in plasma of two paediatric patients with diagnosis of urinary tract infection. The top chromatogram for patient 1 and the bottom for patient 2, where appear TMP (a), internal standard (b) and $\operatorname{SMX}(\mathrm{c})$.

\section{Discussion}

In Mexico, the combination of TMP/SMX is used to treat several infective diseases in children, mainly the urinary tract. As part of a study protocol for children with UTI, was designed a reliable, easy-going, sensible and precise HPLC method for simultaneous determination of TMP and SMX and which could be applied for analysis of both drugs in pharmacokinetic and bioavailability studies. We report herein the result of validation of such method to measure TMP/SMX and for clinical follow-up of the children subjected to this treatment. Currently, we are preparing the manuscript where results of the pharmacokinetics study are described.

The determinations of the concentrations of TMP/SMX were carried out using high resolution liquid chromatographic based on a method previously reported by Sayar et al. [5].

The new method has an important advantage over others that have already been published methods. For example, with shorter retention times of SMX decreases of $9.0 \mathrm{~min}$ at $6.8 \mathrm{~min}$ TMP of $5.0 \mathrm{~min}$ at $3.5 \mathrm{~min}$. Residual contaminants being washed off from the column before each injection and another advantage of this method is that there is no need to adjust $\mathrm{pH}$.

\section{Conclusion}

This method for quantifying TMP/SMX is simple, reliable, fast and specific for its application in pharmacokinetic studies and therapeutic monitoring in paedi- 
atric patients. This analytical method can be used by the Department of Pediatric Infectious Diseases, in patients who need to be treated with TMP/SMX and physicians can meet plasma levels of both drugs on their patients to maintain good control drug and allow adjustments in the dosage if needed quickly and reliably.

\section{Acknowledgements}

We thank to Dr Ciryll Ndidi, an expert traducer that helped us to prepare this manuscript and whose English is his native language.

\section{Conflicts of Interest}

All authors report no conflicts of interest relevant to this article.

\section{References}

[1] Mandell, G.L. and Petri, W.A. (2001) Sulfonamids, Trimethoprim-Sulfamethoxazol and Quinolons Drugs Used against Urinary Tract Infections. In: Goodman and Gilman, Eds., The Pharmacological Basis of Therapeutics, 9th Edition, McGraw Hill, New York, 1123-1140.

[2] Lundstrom, T.S. and Sobel, J.D. (1995) Vancomycin, Trimethoprim Sulfamethoxazol and Rifampin. Infectious Disease Clinics of North America, 9, 747-757.

[3] Dagan, R., Einhorn, M., Lang, R., Pomeranz, A., Wolach, B., Miron, D., Raz, R., Weinstock, A. and Steinberger, J. (1992) Once Daily Cefixime Compared with Twice Daily Trimethoprim/Sulfamethoxazole for Treatment of Urinary Tract Infection in Infants and Children. Pediatric Infectious Disease Journal, 11, 198-203. https://doi.org/10.1097/00006454-199203000-00005

[4] Lindemulder, S. and Albano, E. (2007) Successful Intermittent Prophylaxis with Trimethoprim/Sulfamethoxazole 2 Days per Week for Pneumocystis Carinii (Jiroveci) Pneumonia in Pediatric Oncology Patients. Pediatrics, 120, e47-e51. https://doi.org/10.1542/peds.2006-1360

[5] Sayar, E., Sahin, S., Cevheroglu, S. and Hincal, A.A. (2010) Development and Validation of an HPLC Method for Simultaneous Determination of Trimethoprim and Sulfamethoxazole in Human Plasma. European Journal of Drug Metabolism and Pharmacokinetics, 35, 41-46. https://doi.org/10.1007/s13318-010-0006-9

[6] Bedor, D.C., Gonçalves, T.M., Ferreira, M.L., de Sousa, C.E., Menezes, A.L., Oliveira, E.J. and de Santana, D.P. (2008) Simultaneous Determination of Sulfamethoxazole and Trimethoprim in Biological Fluids for High-Throughput Analysis: Comparison of HPLC with Ultraviolet and Tandem Mass Spectrometric Detection. Journal Chromatography B: Analytical Technology Biomedical Life Science, 863, 46-54. https://doi.org/10.1016/j.jchromb.2007.12.027

[7] Turnipseed, S.B., Clark, S.B., Storey, J.M. and Carr, J.M. (2012) Analysis of Veterinary Drug Residues in Frog Legs and Other Aquacultured Species Using Liquid Chromatography Quadrupole Time-of-Flight Mass Spectrometry. Journal of Agricultural and Food Chemistry, 60, 4430-4439. https://doi.org/10.1021/jf2049905

[8] da Silva, I.S., Vidal, D.T., do Lago, C.L. and Angnes, L. (2013) Fast Simultaneous Determination of Trimethoprim and Sulfamethoxazole by Capillary Zone Electrophoresis with Capacitively Coupled Contactless Conductivity Detection. Journal of Separation Science, 36, 1405-1409.

https://doi.org/10.1002/jssc.201201013 
[9] Official Mexican Norm NOM-177-SSA1-1998 (1998) Guide That Stats the Rules, Proofs, and Procedures to Show That Any Drug Can Be Inter-Change, and Requirements That Labs Must to Follow as Third Authorized to Do Assays. Health Minister, Mexico City. 